\title{
Buen gobierno y derechos humanos en México
}

\author{
Good governance and human rights in Mexico
}

\author{
Gustavo, Aguilera-Izaguirre ${ }^{2}$ \\ Universidad Autónoma del Estado de México, México \\ (iD) https://orcid.org/0000-0002-9817-6746 \\ do) $h$ ttps://doi.org/10.29105/pgc7.13-1
}

\begin{abstract}
RESUMEN
El presente trabajo tiene como objetivo general analizar el pleno ejercicio de los derechos humanos, en el contexto del desarrollo de un buen gobierno en México El presente artículo es una investigación de tipo cualitativo, parte de un diseño no experimental, bajo un nivel documental-bibliográfico trasversal. Del análisis documental se observó que la gestión de los asuntos públicos es el proceso a través del cual las instituciones públicas dirigen los asuntos de interés general, administran los recursos públicos y garantizan la realización de los derechos humanos. La pregunta es: ¿a través del buen gobierno logran las instituciones encargadas de la gestión de los asuntos públicos garantizar eficazmente derechos humanos? Se concluye que la buena gestión de los asuntos públicos logra este resultado esencialmente mediante la eliminación de los abusos y la corrupción, y prestando la debida atención al Estado de derecho. El verdadero criterio que determina si la gestión de los asuntos públicos es "buena" consiste en el grado en que hace realidad las promesas de los derechos humanos: los derechos civiles, culturales, económicos, políticos y sociales.

Palabras claves: Buen Gobierno, Derechos Humanos, Estado de Derecho
\end{abstract}

\begin{abstract}
The general objective of this work is to analyze the full exercise of human rights, in the context of the development of good governance in Mexico This article is qualitative research, part of a non-experimental design, under a transverse documentary-bibliographic level. From the documentary analysis it was noted that the management of public affairs is the process through which public institutions direct matters of general interest, administer public resources and ensure the realization of human rights. The question is: Do the institutions responsible for the management of public affairs effectively guarantee human rights through good governance? It is concluded that good management of public affairs achieves this result essentially by eliminating abuses and corruption, and paying due attention to the rule of law. The real criterion that determines whether the management of public affairs is "good" is the degree to which the promises of human rights come true: civil, cultural, economic, political and social rights. Keywords: Good governance, human rights, rule of law.
\end{abstract}

Recibido: 13 de Julio 2020 - Aceptado: 09 de Septiembre 2020

Cómo referenciar este artículo:

Aguilera-Izaguirre, G. (2021). Buen gobierno y derechos humanos en México. Revista Politica Globalidad y Ciudadanía, 20-40. Recuperado de http://revpoliticas.uanl.mx/index.php/RPGyC/article/view/166. https:// doi.org/10.29105/pgc7.13-1

1 Este artículo es producto del proyecto "Calidad y Buen gobierno", financiado por PROMEP.

2 Doctor por la Universidad de Salamanca, España, Profesor Investigador en la Universidad Autónoma del Estado de México, Correo: gaguilerai@uaemex.mx. 


\section{1.- INTRODUCCION}

La gestión de los asuntos públicos es el proceso a través del cual las instituciones públicas dirigen los asuntos de interés general, administran los recursos públicos y garantizan la realización de los derechos humanos. La buena gestión de los asuntos públicos logra este resultado esencialmente mediante la eliminación de los abusos y la corrupción, y prestando la debida atención al Estado de derecho. El verdadero criterio que determina si la gestión de los asuntos públicos es "buena" consiste en el grado en que hace realidad las promesas de los derechos humanos: los derechos civiles, culturales, económicos, políticos y sociales. La pregunta esencial es la siguiente: ¿logran las instituciones encargadas de la gestión de los asuntos públicos garantizar eficazmente el derecho a la salud, a la vivienda adecuada, a la alimentación suficiente, a la educación de buena calidad, a la buena administración de justicia y a la seguridad personal? (ONU, 2006). El servicio a los intereses generales define la esencia de la administración Pública y determina totalmente su estructura y su actividad. Como organización, la administración debe construirse de la manera más adecuada para alcanzar su fin. Además, los intereses perseguidos por la administración Pública no son, ni particulares, ni privados, solo de carácter general; y además la función de servicio ha de realizarse con objetividad, es decir, sin acepción de personas ni interferencias partidistas, sin favoritismos no discriminaciones (Sánchez, 2008). De lo anterior surge el calificativo que se le asigna a la administración pública en sus efectos que repercuten sobre los ciudadanos, al valorarla como buena o mala administración de acuerdo, a los efectos derivados de su función.

\section{2.- FUNDAMENTO TEÓRICO}

\section{Buen Gobierno}

El concepto de buen gobierno (good governance) se ha difundido ampliamente en la literatura sobre estudios del desarrollo desde principios de los años 90 a raíz de un estudio realizado por el Banco Mundial (World Bank, 1992) sobre la crisis y el crecimiento sostenido en el África Subsahariana [sic] y la importancia del men- 
cionado buen gobierno en el desarrollo económico. Según el estudio, el fracaso en muchos países africanos de las políticas de ajuste estructural se habría debido precisamente a la ausencia de aquél, esto es, al mal gobierno (poor governance) reinante, que habría dificultado las necesarias inversiones extranjeras. Este mal gobierno se caracteriza por problemas como: a) la falta de responsabilidad y de una rendición de cuentas de los poderes públicos; b) la falta de transparencia; c) la escasa capacidad de previsión de los políticos y funcionarios; y d) la ausencia del Estado de derecho (Alberdi, 2006 citado por Pérez de Armiño, 2005: s/p).

Esto quiere decir, según Villoria (2011: 37), que debe existir un buen sistema nacional de integridad, cuyos pilares deben ser la voluntad política en el ejecutivo de prevenir y combatir la corrupción; un sector público competente, objetivo e imparcial, con adecuados sistemas de contratación y distribución de subvenciones; la existencia de un Parlamento activo en la promoción de buena gobernanza y en el combate a la corrupción; un eficaz sistema de auditoría y control contable y financiero; partidos políticos comprometidos con la lucha anticorrupción y que se financian limpiamente; un poder judicial independiente e imparcial, además de competente en la lucha anticorrupción; una defensoría del pueblo y/o [sic] varios sistemas de defensa del ciudadano frente a abusos y mal funcionamiento del servicio público; un organismo central en la detección e investigación de la corrupción, así como en la promoción de medidas de prevención de la misma; [...] y una sociedad civil bien informada e implicada en la lucha contra los abusos de los poderes públicos y privados.

Las anteriores son acciones que han venido a reforzar la estrategia conducente a establecer un orden en la funcionalidad de los gobiernos y sus administraciones, como la actuación correcta de los funcionarios y los servidores públicos, la consolidación de la existencia de ciertos valores como el respeto al interés general y la honestidad, así como lograr la consolidación de los sistemas democráticos, en función del ciudadano. 
Diferentes Nociones acerca del Buen Gobierno, por parte de Organismos Internacionales.

Diferentes organismos internacionales han procedido a llevar a cabo diversos programas a favor del buen gobierno en los países en desarrollo. Ahora bien, tal vez por su contenido netamente político, la noción de buen gobierno presenta significados no plenamente coincidentes para diferentes instancias, como, por ejemplo:

Las instituciones ubicadas en el llamado Consenso de Washington (gobierno de los EE.UU., FMI (Fondo Monetario Internacional) y Banco Mundial), aunque con algunas diferencias, proponen agendas de buen gobierno centradas no tanto en el tipo de régimen político, sino más bien en determinadas características del proceso de gobernabilidad, como son la rendición de cuentas, la transparencia y el estado de derecho. Ahora bien, mientras el gobierno norteamericano suele hacer más hincapié en temas relacionados con la democracia y los derechos civiles, el FMI se ha centrado en la reducción de los gastos militares, en tanto que el Banco Mundial ha manejado una agenda más amplia y menos definida.

Por su parte, el PNUD (Programa de Naciones Unidas para el Desarrollo) lo contempla con claves más ambiciosas, que guardan coherencia con su concepto del desarrollo humano. El PNUD interpreta el gobierno (governance) de un país como el ejercicio de la autoridad económica, política y administrativa para manejar los asuntos de un país en todos los niveles a fin de que el Estado promueva la cohesión social, la integración y el bienestar de su población. Por tanto, el buen gobierno requiere la participación pública, para asegurar que las prioridades políticas, sociales y económicas estén basadas en un amplio consenso social, así como que las poblaciones más pobres y vulnerables puedan incidir directamente en el proceso político de toma de decisiones.

El PNUD dispone de un programa de buen gobierno que se centra en las instituciones de gobierno, la gestión de los sectores públicos y privados, la descentralización, las organizaciones de la sociedad civil y los gobiernos de países en transición a la economía de mercado. En definitiva, la concepción del buen gobierno 
del PNUD es más amplia que otras, teniendo en cuenta elementos como los factores culturales, las particularidades nacionales, los liderazgos y la responsabilidad política, los procesos de participación social, así como la construcción de capacidades. El Programa de las Naciones Unidas para su Desarrollo propuso una serie de principios para definir las características de la buena gobernanza desde el punto de vista de las relaciones entre Estado y sociedad. Esos principios o características son: Estado de Derecho (imparcialidad), legitimidad y voz (participación y orientación para el consenso), transparencia y rendición de cuentas, rendimiento (capacidad de respuesta, eficacia, eficiencia), dirección (visión estratégica) y equidad (acceso universal, incluidas las minorías, a oportunidades de mantener y mejorar el bienestar propio).

Por último, diferentes sectores y autores critican la noción de buen gobierno por la subjetividad que encierra la definición de qué países lo cumplen y cuáles no; así como, sobre todo, por entender que éste y otros criterios de condicionalidad política de la ayuda representan una violación de la soberanía de los países receptores. En otras palabras, lo ven como un mecanismo encubierto de los países occidentales para perpetuar su control político sobre los países pobres. Algunos autores añaden que la condicionalidad del buen gobierno se emplea como un argumento más para justificar los recortes de la ayuda internacional. En general, estos críticos defienden que el buen gobierno debería interpretarse más bien como la práctica de aquellos gobiernos que trata de maximizar los beneficios sociales de sus políticas (Alberdi, 2006 citado por Pérez de Armiño, 2005: s/p).

En conclusión, la mayoría de los organismos internacionales, donantes de cooperación al desarrollo han insistido en la necesidad del buen gobierno en los países receptores; el cual se ha convertido en uno de los principales criterios políticos de condicionalidad para la concesión de aquélla. al considerarlo como un tipo de ejercicio del poder que garantiza el crecimiento económico, la democracia pluripartidista, la economía de mercado, el respeto a los derechos humanos, la reducción del gasto militar $\mathrm{y}$, en algunos casos, la equidad socioeconómica.

La Declaración del Milenio, del 13 de septiembre de 2000, señala en el punto 24 
"No escatimaremos esfuerzo alguno por promover la democracia y fortalecer el imperio del derecho y el respeto de todos los derechos humanos y las libertades fundamentales internacionalmente reconocidos, incluido el derecho al desarrollo"; mientras que en el punto 25 Decidimos, por tanto, respetar y hacer valer plenamente la Declaración Universal de Derechos Humanos. Esforzarnos por lograr la plena protección y promoción de los derechos civiles, políticos, económicos, sociales y culturales de todas las personas en todos nuestros países (ONU, 2000: $\mathrm{s} / \mathrm{p})$.

Otros de los aspectos señalados son:

Aumentar en todos nuestros países la capacidad de aplicar los principios y las prácticas de la democracia y del respeto de los derechos humanos, incluidos los derechos de las minorías.

Luchar contra todas las formas de violencia contra la mujer y aplicar la Convención sobre la eliminación de todas las formas de discriminación contra la mujer.

Adoptar medidas para garantizar el respeto y la protección de los derechos humanos de los migrantes, los trabajadores migratorios y sus familias.

Eliminar los actos de racismo y xenofobia cada vez más frecuentes en muchas sociedades y promover una mayor armonía y tolerancia en todas las sociedades.

Garantizar la libertad de los medios de difusión para cumplir su indispensable función y el derecho del público a la información (ONU, 2000: s/p).

Es así que la Declaración del Milenio presenta para el siglo XXI una visión de un mundo pacífico, próspero y justo, que reafirma los propósitos y los principios de la Carta de las Naciones Unidas; refleja el compromiso de los Estados Miembros de lograr la paz, la seguridad y el desarme; promover el desarrollo y la erradicación de la pobreza; proteger nuestro entorno común; defender los derechos humanos, la democracia y el buen gobierno; entre otras cosas (ONU, 2002: 1). 
Al analizar el papel del buen gobierno en la aplicación de la Declaración, es necesario prestar particular atención a los elementos básicos de la capacidad para gobernar, a saber, [sic] la capacidad institucional, la capacidad de formulación de políticas, la capacidad administrativa o de gestión, el perfeccionamiento de los recursos humanos y la suficiencia tecnológica. Una de las conclusiones principales que pueden extrapolarse de la Declaración y sus objetivos es que la capacidad del Estado en las esferas mencionadas es el factor primordial para su aplicación satisfactoria. Un gobierno democrático eficaz y una administración pública [sic] eficiente se cuentan, sin duda alguna, entre los elementos más importantes de la promoción del programa de desarrollo nacional de un país (ONU, 2002: 1 y 3).

En marzo de 2006, la Asamblea General de la Organización de las Naciones Unidas emitió la resolución A/RES/60/34, en la cual se le pidió a la comunidad internacional que "preste más apoyo a las iniciativas nacionales en materia de Administración Pública, en particular las de los países en desarrollo [...], y a las alianzas entre el sector público y el privado, a fin de proporcionar [...] apoyo educacional, material y técnico y cooperación" (ONU, 2006: 2). Además, se le solicitó a los Estados Miembros que "respeten los principios de debida gestión de los asuntos y los bienes públicos, equidad, responsabilidad e igualdad ante la ley y la necesidad de salvaguardar la integridad y fomentar una cultura de transparencia, rendición de cuentas y rechazo de la corrupción en todos los niveles y en todas sus formas, de conformidad con la Convención de las Naciones Unidas contra la Corrupción" (ONU, 2006: 2).3 Ahora bien, Villoria (2016) refiere que los componentes axiológicos del buen gobierno son la efectividad, la profesionalidad y la imparcialidad, la transparencia, la participación y la rendición de cuentas. Para los efectos de este artículo, se analizarán algunos de éstos:

a) La efectividad es entendida como la capacidad de producir objetivos deseados en la esfera social y económica a través de las actuaciones y los instrumentos gubernamentales centrados en la eficiencia y la economía. b) La profesionalidad se refiere a la forma en la que la burocracia debe desempeñar sus funciones con rigor técnico y jurídico y con estabilidad para servir objetivamente al interés general. 
c) La imparcialidad es una forma de actuación que no es alterada por cierto tipo de consideraciones, como las relaciones privilegiadas o las preferencias personales. d) La transparencia se define como el flujo incremental de la información oportuna y confiable de carácter económico, social y político, accesible a todos los actores relevantes. e) La rendición de cuentas se define como un proceso a través del cual los gobernantes, los representantes y los servidores públicos informan, responden, justifican sus actos, sus decisiones y sus planes de acción a los gobernados y se sujetan a las sanciones y las recompensas procedentes. f) La participación es un proceso social en el que intervienen de manera permanente los derechos y las responsabilidades, porque intenta dar a cada individuo un encargo en la medida que pueda comprometerse, donde en cada nivel habrá un interés y una capacidad para asumirlo de forma total o compartida. La participación debe ser vista como un medio para lograr una gestión eficiente, ya que crea una relación de mayor compromiso e integración al grupo (Burin, Istvan y Levin, 1998, citados por el Centro de Estudios Sociales y de Opinión Pública, 2017: 2). La participación tiene un papel fundamental en las democracias, prueba de ello es que desde la teoría democrática tradicional se observa que los ciudadanos se interesan por la política y participan en ella, conocen los procesos de gobierno y las alternativas de solución que se proponen para enfrentar problemas públicos y votan con base en valores y principios (Conway, 1986 citada por el Centro de Estudios Sociales y de Opinión Pública, 2017: 3). Desde esta óptica, construir un derecho humano a la buena Administración Pública sólo requiere un cambio de paradigma interpretativo: una Administración Pública al servicio del ser humano. El derecho a la buena administración también se relaciona con lo que concierne a la ética y los buenos modales en el servicio público.

Se ha observado que, además de la Carta de los Derechos Fundamentales de la Unión Europea, en la cual figura la proclamación específica del derecho a una buena administración; también se han elaborado, por parte de organismos y Estados, códigos, cartas o instrumentos destinados a mejorar la conducta de quienes tienen la responsabilidad de prestar los servicios públicos. En Europa, por ejemplo, se expidió el llamado Código de Buena Conducta Administrativa para el Personal 
de la Comisión Europea en sus Relaciones con el Público, con éste: la Comisión dio un importante paso concreto con vistas a la aplicación de dichos principios al adoptar, el 13 de septiembre de 2000, un código de buena conducta administrativa. Dicho código representa una valiosa guía para los funcionarios de la Comisión en sus relaciones con el público4 [...] El objetivo de este código consiste, por lo tanto, en reforzar los esfuerzos ya desplegados en este sentido, garantizando en toda circunstancia un servicio de calidad e informando al público de las normas de conducta que tiene derecho a esperar en sus relaciones con la Comisión. A estos efectos, el Código define los principios en [sic] que deben basarse las relaciones entre la Comisión y el público: legalidad, no discriminación, proporcionalidad de las medidas con los objetivos perseguidos y coherencia en el comportamiento administrativo (Kinnock, en la Comisión Europea, s/f: 1).

Otro de los instrumentos en esta materia es el Código Iberoamericano de Buen Gobierno, del 23 de junio de 2006, (CLAD,2006) el cual se aplicó a los presidentes de república, los vicepresidentes, los presidentes del gobierno o del Consejo de Ministros, los primeros ministros, los jefes del gabinete de ministros, los ministros, los secretarios de Estado o equivalentes y, en general, a todos los altos cargos del Poder Ejecutivo, tales como viceministros, subsecretarios, directores de entes públicos o directores generales. En éste, se establecieron, además de los principios y los valores, los principios básicos que guiarán la acción del buen gobierno: a. El respeto y reconocimiento de la dignidad de la persona humana. b. La búsqueda permanente del interés general. c. La aceptación explícita del gobierno del pueblo y la igualdad política de todos los ciudadanos y los pueblos. d. El respeto y promoción de las instituciones del Estado de Derecho y la justicia social. Los valores que guiarán la acción del buen gobierno son, especialmente: Objetividad, tolerancia, integridad, responsabilidad, credibilidad, imparcialidad, dedicación al servicio, transparencia, ejemplaridad, austeridad, accesibilidad, eficacia, igualdad de género y protección de la diversidad étnica y cultural, así como del medio ambiente (Centro Latinoamericano de Administración para el Desarrollo, 2006: 3).

En ellos se regirá, la definición de un buen gobierno, como “aquél que busca y 
promueve el interés general, la participación ciudadana, la equidad, la inclusión social y la lucha contra la pobreza, respetando todos los derechos humanos, los valores y procedimientos de la democracia y el Estado de Derecho", así como "los tres tipos de reglas de conducta las vinculadas a: la naturaleza democrática del gobierno, a la ética gubernamental y a la gestión pública" (Centro Latinoamericano de Administración para el Desarrollo, 2006: 3 y 4).

Otra de las definiciones de buen gobierno y que se vincula con la definición anterior es la señalada por (Castro, 2014: 248) en la que el buen gobierno es el adecuado y responsable ejercicio del poder y del cumplimiento de los deberes de función estatal, garantizando la realización de los derechos humanos y la protección del interés público, proveyendo marcos institucionales transparentes y participativos para el eficaz funcionamiento del aparato estatal en el marco de un Estado Social y Democrático de Derecho, como medio para asegurar el desarrollo de todos los miembros de la sociedad en condiciones dignas y de igualdad.

\section{Derechos Humanos}

Los derechos humanos son el conjunto de derechos por los cuales se afirma la dignidad de la persona frente al Estado, es decir, son derechos públicos subjetivos que tienen la correlativa obligación las limitaciones, obligaciones o prestaciones que ha de servir el estado en favor del individuo. En su aspecto positivo son aquellos derechos reconocidos por el sistema jurídico de que se trate, en el caso de México serían los que se establecen en la constitución política de los Estados Unidos mexicanos, además de lo que se recogen en los pactos convenciones y tratados internacionales suscritos y ratificados por el estado mexicano. (Orozco, 20002).

Los conceptos de derechos humanos, derechos fundamentales y garantías invaluables no son equivalentes, ni tampoco se pueden utilizar indistintamente. (Pérez Luño, 200I: 48) señala al respecto que: los derechos humanos son un conjunto de facultades e instituciones que, en cada momento histórico, concretan las exigencias de la dignidad, la libertad y la igualdad humanas, las cuales deben ser recono- 
cidas positivamente por los ordenamientos jurídicos a nivel nacional e internacional; y los derechos fundamentales son aquellos derechos humanos garantizados por el ordenamiento jurídico positivo, en mayor parte de los casos en su normatividad constitucional y que suelen gozar de una tutela reforzada. En cuanto a la garantía decimos que es el medio. En sentido moderno una garantía constitucional tiene por objeto reparar las violaciones que se hayan producido a los principios, valores o disposiciones fundamentales. Al respecto existe jurisprudencia en la que se señala que las garantías individuales no son derechos sustantivos, sino que constituyen el instrumento constitucional para salvaguardar éstos, es decir, constituye el instrumento constitucional establecido por la propia norma fundamental del país para salvaguardar tales derechos. (Semanario Oficial de la Federación, 1996)

Cuando hablamos de garantías jurídicas nos referimos a las disposiciones jurídicas que tienden hacer efectivas y tutelar la vigencia del derecho. Pero cuando nos referimos a las garantías de los derechos humanos, no solo nos referimos a los mecanismos jurídicos creados en la norma jurídica para su protección y defensa, sino a los aspectos económicos, sociales y culturales necesarios para lograr su eficacia. (Hernández, 2015)

En este sentido, cuando abordamos lo relacionado a los derechos económicos, sociales y culturales como aquellos que están vinculados a la satisfacción de las necesidades básicas de las peronistas en ámbitos como el trabajo, la alimentación, la salud, la vivienda, la seguridad social, la educación, la cultura, el agua y el medio ambiente. Hubo un momento en el que se generó la idea equivocada de que cada categoría de derechos tenía una naturaleza jurídica distinta y enorme aun que mientras los derechos civiles y políticos si eran derechos humanos vinculantes y de realización inmediata por parte de los estados, los DESC eran derechos programáticos cuya realización no podía exigirse directamente a los estados y se encontraba condicionada a factores tales como la disposición de recursos económicos. Hoy en día esta distinción entre ambas categorías ha sido superada y se reconoce ampliamente la indivisibilidad y la interdependencia e interrelacionarse de todos los derechos humanos. (ACNUDH, 2010:) 
Se debe entender que todos los derechos humanos implican para los estados las mismas obligaciones, que son de tres tipos: la obligación de respetar, que consiste en abstenerse de impedir u obstaculizar la realización de los derechos de las personas; la obligación de proteger, que consiste en adoptar las medidas para evitar que las terceras personas puedan restringir o anular los derechos humanos de otras personas y la obligación de realizar, la cual conste en adoptar las medidas positivas para garantizar que las personas puedan acceder al ejercicio de sus derechos humanos, aun y cuando no puedan hacerlo por sus propios medios y recursos.

En general, las normas que establecen derechos humanos de carácter colectivo, los derechos económicos, sociales, culturales y ambientales, tienen el carácter de normas programáticas. Las normas programáticas son de existencia reciente en los diversos sistemas jurídicos y generalmente pretenden atender a la dinámica y a las necesidades sociales que el Estado debe cubrir como un de sus fines. Verificar la eficacia de estas normas y garantizar su cumplimiento de sus objetivos es hoy en día una de las tareas pendientes de mayor relevancia en el campo de los derechos humanos (Hernández, 2015).

\section{Los derechos humanos y el buen gobierno en México}

En la Constitución Política de los Estados Unidos Mexicanos no recoge de forma explícita en su texto nor $\neg$ mativo el derecho a la buena administración o buen gobierno. Sin embargo, si se observan los principios constitucionales relativos a la actuación de los poderes públicos, se rastrean algunos de los rasgos esenciales de esta noción. En este sen $\neg$ tido, se puede corroborar cómo existe un paralelismo entre los objetivos que se proponen para el principio de la buena administración y aquellos compromisos constitucionales que tratan de materializar el modelo de Estado social y demo $\neg$ crático de derecho en México. Así, por ejemplo, si tenemos en cuenta que el derecho a la buena administración abarca principios como: participación, trasparencia, rendición de cuentas o accountability, eficacia y coherencia, las anteriores tienen su existencia normativa en nuestra Carta Magna. (Aguilera, 2018) 
En la Constitución Política de los Estados Unidos Mexicanos, en los tratados internacionales que México ha ratificado y en las leyes de procedimiento administrativo, se encuentran contenidos los principios que sirven de garantía para el administrado dentro del procedimiento administrativo. Las normas jurídicas constitucionales y supranacionales, que son de jerarquía superior a cualquier otra norma del sistema jurídico, consagran principios jurídicos que a lo largo de la historia han ido tomando un protagonismo importante dentro del procedimiento administrativo, y que, en la actualidad, desconocerlos, resulta casi imposible. La finalidad del procedimiento administrativo consiste en el dictado de un acto administrativo y para llevar a cabo dicha finalidad, se deben respetar ciertos principios que tienen por objetivo que, dentro del menor tiempo posible y reuniendo la mayor cantidad de información, se pueda declararla voluntad de la administración pública.

Incluso se puede afirmar que en el derecho mexicano existen algunos principios del derecho a la buena administración en otros derechos humanos fundamentales ya establecidos en nuestra constitución. Podemos deducir que el derecho a la buena administración forma parte integrante del resto de los derechos. Los artículos $6^{\circ}$ de reciente reforma establece ya el derecho de acceso a la información; el art. $8^{\circ}$ que encierra el derecho de petición (Instituto Federal del Acceso a la Información, 2004); el art.14 ${ }^{\circ}$ que consagra el principio de legalidad; el art. $16^{\circ}$ el cual protege la libertad personal y la seguridad por medio de la legalidad, de la motivación y fundamento que se requiere para los actos de autoridad que causen molestia a los individuos en su persona, papeles y posesiones, de nuestra constitución, son un claro ejemplo de derecho que se encuentran establecidos de lo que conocemos ya como el derecho a la buena administración pública. (Aguilera,2018)

En líneas anteriores mencionábamos que una característica distintiva de los derechos humanos es su reconocimiento en los ordenamientos jurídicos de la más alta jerarquía normativa de los Estados, esto es, en los Textos Fundamentales. El 10 de junio de 2011 se publicó en el Diario Oficial de la Federación (DOF) la reforma que logró la incorporación formal de los derechos humanos a la Constitución Política de los Estados Unidos Mexicanos (CPEUM). Junto con otras dos 
reformas, representan un conjunto muy relevante de reformas que tienen gran impacto en el sistema jurídico mexicano. Las reformas inciden sustancialmente en las instituciones sociales y estatales, y tocan aspectos jurídicos torales relacionados con la promoción, el reconocimiento y el respeto de los derechos humanos de toda persona ubicada en territorio nacional. La reforma acompaña a la ocurrida en materia penal ( $D O F$ del 18 de junio de 2008) y en materia de amparo ( $D O F$ del 6 de junio de 2011).

En México, el párrafo tercero de la Constitución obliga a todas las autoridades, en el ámbito de sus respectivas competencias, a observar las siguientes garantías... tienen la obligación de promover, respetar, proteger y garantizar los derechos humanos de conformidad con los principios de universalidad, interdependencia, indivisibilidad y progresividad. En consecuencia, el Estado deberá prevenir, investigar, sancionar y reparar las violaciones a los derechos humanos, en los términos que establezca la ley.

Por tal motivo el buen gobierno y los derechos humanos se vinculan y refuerzan entre sí, ya que, sin la existencia de un buen gobierno, los derechos humanos no pueden ser respetados y protegidos de manera sostenible. Para el ejercicio de los derechos humanos entonces, se requiere que exista un entorno propicio en el cual existan instituciones y marcos jurídicos apropiados, así como también, una administración responsable de satisfacer las necesidades de la población.

La Oficina del Alto Comisionado de las Naciones Unidas para los Derechos $\mathrm{Hu}-$ manos (ACNUDH, 2008) llevo a cabo un estudio de prácticas de buen gobierno, y en él señaló que los vínculos entre el buen gobierno y los derechos humanos se dan en cuatro esferas: instituciones democráticas, prestación de servicios del Estado, Estado de derecho y medidas contra la corrupción. Se exponen distintas formas en que diversos agentes sociales e institucionales, desde grupos de mujeres o de minorías hasta los medios de información, la sociedad civil o los organismos del Estado, han llevado a cabo reformas en esos cuatro ámbitos.

Cuando están orientadas por los valores de los derechos humanos, las reformas 
de las instituciones democráticas con arreglo al buen gobierno crean vías para la participación de los ciudadanos en la formulación de políticas, sea por conducto de las instituciones estructuradas o mediante mecanismos informales de consulta. También establecen mecanismos para la inclusión de múltiples grupos sociales en los procesos de adopción de decisiones, especialmente a nivel local. Por último, pueden alentar a la sociedad civil y a las comunidades locales a formular y expresar sus posiciones sobre cuestiones importantes para ellas.

En el ámbito de la prestación de servicios del Estado a la población, las reformas de la gobernanza promueven los derechos humanos cuando mejoran la capacidad del Estado para cumplir su responsabilidad de ofrecer bienes públicos indispensables para la protección de cierto número de derechos humanos, como el derecho a la educación, a la salud y a la alimentación. Las iniciativas de reforma pueden incluir mecanismos de rendición de cuentas y transparencia, herramientas de política atentas a los aspectos culturales para garantizar que los servicios sean accesibles y aceptables para todos, y vías de participación ciudadana en la adopción de decisiones.

En lo que se refiere al Estado de derecho, las iniciativas de gobernanza que tienen en cuenta los derechos humanos reforman la legislación y ayudan a las instituciones, desde los sistemas penales hasta los tribunales y los parlamentos, aplicar mejor esa legislación. Las iniciativas de gobernanza pueden incluir la promoción de reformas legales, la sensibilización del público sobre el marco jurídico nacional e internacional, y el aumento de la capacidad o la reforma de instituciones.

Por último, las medidas contra la corrupción también forman parte del marco de la buena gobernanza. Aunque aún no se han estudiado en profundidad los vínculos entre la corrupción, las medidas anticorrupción y los derechos humanos, el movimiento contra la corrupción está acudiendo al ámbito de los derechos humanos para impulsar sus esfuerzos. Para combatir la corrupción, los esfuerzos de buen gobierno se apoyan en principios como la rendición de cuentas, la transparencia y la participación para dar forma a las medidas de lucha. Las iniciativas pueden incluir el establecimiento de instituciones como comisiones anticorrupción, la 
creación de mecanismos de intercambio de información y la vigilancia del uso de fondos públicos, y la aplicación de políticas por parte de los gobiernos.

\section{3.- MÉTODO}

\section{Diseño}

Esta investigación es de tipo cualitativo, no experimental, al ser utilizada como procedimiento metodológico que utiliza textos, discursos, para construir un conocimiento de la realidad social, llevando a cabo un proceso de construcción y comprobación teórica desde una perspectiva holística, pues se trata de comprender el conjunto de cualidades interrelacionadas que caracterizan a un determinado fenómeno. La investigación cualitativa busca una aproximación a la realidad social a partir de la obtención de datos no cuantitativos. Para la realización del presente trabajo se empleó la técnica documental.

\section{Instrumentos}

Para la composición del marco teórico, se empleó la técnica de investigación documental, a través de una exhaustiva revisión de la bibliografía en relación con derechos humanos y al buen gobierno, en México y en otros países, así como también de organismos internacionales, motivo por el cual se analizaron fuentes internacionales y en virtud de ello se empleó el método comparativo, por medio del ejercicio de la lectura comprensiva en donde se analizaron con un enfoque crítico

\section{Procedimientos}

Se realizó una revisión y análisis compresivo, crítico y comparativo de las fuentes que están íntimamente relacionadas con el objeto de estudio, la cual es suficiente en materia de derechos humanos no así en cuanto al buen gobierno en México, motivo por el cual se analizaron fuentes internacionales y en virtud de ello un análisis comparativo. Posterior a ello se realizaron conclusiones.

\section{4.- CONCLUSIONES}

Al principio de este documento señalábamos que el verdadero criterio que deter- 
mina si la gestión de los asuntos públicos es "buena" consiste en el grado en que hace realidad las promesas de los derechos humanos: los derechos civiles, culturales, económicos, políticos y sociales. ¿La pregunta esencial que nos hacíamos era si el Estado ha logrado garantizar eficazmente los derechos humanos?

A lo largo del presente trabajo establecimos que tanto el buen gobierno y de derechos humanos se fortalecen mutuamente y tienen en común, principios fundamentales, como lo son, la participación, rendición de cuentas, transparencia y responsabilidad. De hecho, los derechos humanos requieren de un entorno favorable y propicio, en particular reglamentos, instituciones y procesos adecuados que encuadraran las medidas adoptadas por el Estado. Los derechos humanos proporcionan un conjunto de normas de desempeño con respecto a las cuales poda exigirse responsabilidad a los gobiernos y otros agentes. Al mismo tiempo, las políticas de buen gobierno deben hacer posible que las personas vivan con dignidad y libertad. Para que los derechos humanos, puedan respetarse y protegerse de manera sostenible requieren de la existencia de un buen gobierno en el Estado Mexicano. Se concluye que la buena gestión de los asuntos públicos logra este resultado esencialmente mediante la eliminación de los abusos y la corrupción, y prestando la debida atención al Estado de derecho. El verdadero criterio que determina si la gestión de los asuntos públicos es "buena" consiste en el grado en que hace realidad las promesas de los derechos humanos: los derechos civiles, culturales, económicos, políticos y sociales.

En la actualidad se siguen llevando a cabo acciones políticas, económicas, sociales, pero sobre todo jurídicas, a fin de que los derechos humanos sean realmente eficaces y garantizar por todas las vías posibles el cumplimiento de sus objetivos. En este sentido, en nuestro país México, como ya lo habíamos señalado en líneas anteriores y acorde a nuestra Ley Suprema "todas las autoridades, en el ámbito de sus competencias, tienen la obligación de promover, respetar, proteger y garantizar los derechos humanos" luego entonces, los tres poderes, Ejecutivo, Legislativo y Judicial, deberán de llevar a cabo todas las acciones necesarias a fin de dar cumplimiento a los establecido en nuestra Constitución; por un lado el Poder 
Ejecutivo deberá planear e implementar políticas públicas eficaces; el Poder Legislativo deberá de crear normas que establezcan procedimientos, competencias y responsabilidades y el Poder Judicial deberá fallar los casos que resuelve interpretando la norma de la forma que mejor potencié dichos derechos. Respecto de la autoridad administrativa (gobierno), destaca además la directriz contenida en el párrafo segundo del apartado A del artículo 26 constitucional, que ordena: "los fines del proyecto nacional contenidos en esta Constitución determinarán los objetivos de la planeación".

\section{REFERENCIAS}

ACNUDH (2008). Prácticas de buen gobierno para la protección de los derechos humanos. México: Oficina En México del alto comisionado de naciones unidas para los derechos humanos (ONU-DH México).

ACNUDH (2010). Los derechos económicos, sociales y culturales: exigibles y justiciables preguntas y respuestas sobre los desc y el protocolo facultativo del pacto internacional de derechos económicos, sociales y culturales. México. Espacio de coordinación de organizaciones civiles sobre derechos económicos, sociales y culturales (espacio desc. México: plataforma interamericana de derechos humanos, democracia y desarrollo (pidhdd), Oficina en México del alto comisionado de naciones unidas para los derechos humanos (ONU-DH México). https://www.hchr.org.mx/images/doc_pub/PIDESClibro.pdf

Aguilera, G. (2018). El derecho humano a la buena administración como prevención a la corrupción en México. Dignitas, XII (34), 117-143.

Alberdi, J. (2006). Buen Gobierno. Citado Por Karlos Pérez De Armiño (Dir.), En diccionario de acción humanitaria y cooperación al desarrollo. Http://Www. Dicc.Hegoa.Ehu.Es/Listar/Mostrar/24. 
Burin, D.; Istvan, K. y Levin, L. (1998). Hacia una gestión participativa y eficaz. citados por el centro de estudios sociales y de opinión pública. En Contexto participación ciudadana, política y electoral en México: hacia la civil toma de decisiones. Http://Www5.Diputados. Gob.Mx/Index.Php/Camara/CentrosDe-Estudio/Cesop/Novedades/En-Contexto.-Participacion-CiudadanaPolitica-Y-Electoral-Enmexico-Hacia-La-Civil-Toma-De-Decisiones.

Castro, A. (2014). Legalidad, buenas prácticas administrativas y eficacia en el sector público: un análisis desde la perspectiva jurídica del buen gobierno. buen gobierno y derechos humanos. Lima: Facultad de Derecho, Pontificia Universidad Católica del Perú.

Centro Latinoamericano de Administración para el Desarrollo -CLAD (2006). Código Iberoamericano De Buen Gobierno. https://clad.org/wp-content/ uploads/2020/04/codigoiber-2.pdf.

Conway, M. M. (1986). La Participación política en Estados Unidos, citada por el centro de estudios sociales y de opinión pública, En Contexto Participación Ciudadana, Política Y Electoral En México: Hacia La Civil Toma De Decisiones. Http:/Www5.Diputados.Gob.Mx/Index.Php/ Camara/CentrosDe-Estudio/Cesop/Novedades/En-Contexto.-Participacion-CiudadanaPolitica-Y-Electoral-En-Mexico-Hacia-La-Civiltoma-De-Decisiones.

Diario Oficial de la Federación - DOF (2011). Decreto por el que se modifica la denominación del Capítulo I del Título Primero y reforma diversos artículos de la Constitución Política de los Estados Unidos Mexicanos. México: Autor.

Diario Oficial de la Federación - DOF (2008). Decreto por el que se reforman y adicionan diversas disposiciones de la Constitución Política de los Estados Unidos Mexicanos. México: Autor.

Hernández, A. (2015). Eficacia constitucional y derechos humanos. México: Comisión Nacional de Derechos Humanos. 
Instituto Federal de Acceso a La Información - IFAI (2004). El derecho de acceso a la información en México: un diagnóstico de la sociedad. México: Editorial Dirección General de Atención a la Sociedad y Relaciones internacionales.

Kinnock, N. (S/F). Código de buena conducta administrativa para el personal de la comisión europea en sus relaciones con el público (Comisión Europea). Http://Www.Eecp.Edu.Mx/Luis_Pablo/Fyep/Ue.Pdf.

Organización de las Naciones Unidas - ONU (2000). Declaración del milenio. https://www.un.org/spanish/milenio/ares552.pdf.

Organización de las Naciones Unidas - ONU (2002). El papel fundamental de la administración pública y el buen gobierno. En La aplicación de la declaración del milenio: ampliación de la capacidad institucional. Informe de la secretaría.

Organización de las Naciones Unidas-ONU (2006). A/Res/60/34. Administración Pública Y Desarrollo. https://undocs.org/pdf?symbol=es/A/RES/60/34

Organización de las Naciones Unidas - ONU (2006). Conferencia de las Naciones Unidas sobre medidas anticorrupción, buen gobierno y derechos humanos. https://www2.ohchr.org/spanish/issues/development/governance/index.htm

Orozco Henríquez, J. (2002). Los Derechos Humanos de los Mexicanos México. México: Comisión Nacional de los Derechos Humanos.

Pérez Luño, E. (2001). Derechos Humanos, Estado de Derecho y Constitución. Madrid: Tecnos.

Sánchez Morón, M. (2008). Derecho Administrativo, parte general. Madrid: Tecnos.

Semanario Oficial de la Federación, (1996). Tesis del Sexto Tribunal Colegiado en Materia Civil del Primer Circuito, que este órgano comparte, visible en la página 547, del Tomo IV, octubre de 1996, Novena Época, Pleno, Salas y Tribunales Colegiados de Circuito, del Semanario Judicial de la Federación y su Gaceta, que establece: Garantías individuales. no son derechos sustantivos, sino que constituyen el instrumento constitucional para salvaguardar esto. 
40

Villoria, M. (2011). El empleo público en tiempos de incertidumbre: ¿continuidad o reforma? empleo público y código ético: la necesidad de reforzar los valores públicos de una institución cuestionada. Revista Aragonesa de Administración Pública, 13, $21-59$.

Villoria, M. (2016). Ética Pública y Buen Gobierno. Madrid: Tecnos.

World Bank (1992). Governance and Development. Washington: Autor. 